\title{
Hemangio-pericytoma of the nasal cavity: about two cases report
}

\begin{abstract}
Summary
The hemangiopericytoma (HP) is a rare intranasal vascular tumor, slow growth .Few symptoms initially, it is difficult to diagnose. The clinician will be alerted by persistent unilateral nasal symptoms and endoscopic appearance of a polypoid tumor raspberry gray the diagnosis is histological, but the biopsy is delicate accounted. The diagnosis is histological but biopsies are delicate because of the risk hemorrhagic malignant potential of this tumor requires surgical removal. The balance sheet includes a pre therapeutic sinonasal scan with iodine injection and imaging resonance (IRM). Some offer arteriography with embolization preoperative. The surgical technique remains the reference paralateronasal way but exerese endoscopically have recently been reported.
\end{abstract}

Keywords: hemangiopericytoma, sinonasal tumour, endonasal surgery, embolization
Volume 3 Issue 4 - 2016

\author{
Zakaria Chafiki, Khdim M, Ait el kerdoudi M, \\ Rouadi S, Abada RL, Roubal M, Mahtar M \\ Hopital 20 Aout, Morocco
}

\begin{abstract}
Correspondence: Zakaria Chafiki, Hopital 20 Aout, ENT Service, CHU Ibn Rushd, Rue 266, Num 48 haymoulayabdellah, Casablanca, Morocco, Email zakaria.chafiki@gmail.com
\end{abstract}

Received: September 20, 2016 | Published: September 23, 2016

\section{Introduction}

Hemangiopericytoma are rare vascular tumors. The sinonasal area represents only $5 \%$ of its locations. ${ }^{1}$ The first case of nasal hemangiopericytoma has been described by Murray and stout in 1942 . Nasal location has specific characteristics that differentiate it from other hemangiopericytomas.

\section{Objectives and methods}

Through this observation we report 2 cases of sinonasal hemangiopericytoma operate in our service by an update on the clinical presentation, diagnostic paraclinical means and support therapeutic.

\section{Results}

\section{Clinical case I}

Mr. HA age 69, without antecedent of facial trauma that had a chronic dysfunction rhinosinusal for 2 months associan nasal obstruction and rhinorrhea anterior right with episodes of epistaxis. symlptomatology has complicated one month after the appearance of a mass of the left nasal cavity inflammatory that was in contact with the nasal septum obstructing the nasal Cavity and bleeding on contact (Figure 1). The scan realized with contrast injection has evidence a process taking tissue contrast serpiginous way of the left nostril occupying the left nasal cavity depends on the nasal cavity depends on the nasal turbinate inferior. It measures 40/20/70. The patient has benefited from a biopsy through endonasal under local anesthesia, the pathological examination the diagnosis of a patient was hemangiopericytomas sinonasal and le operates by endonasal route after an embolisation. The bleeding was controlled by bipolar electrocautery and by compression of wicks soaked adrenaline the patient was seen in consultation and monitoring by rhinocavoscopies without detectable lesions.

\section{Clinical case 2}

Mr. TM age 47 without antecedent of facial trauma, presenting for
5 months of intermittent epistaxis associated moderate has a right nasal obstruction and anosmia, the evolution was marked by exophthalmos with decreased visual acuity and headache intermittences, the objective endonasal examination has a burgeoning mass bleeding in contact obstructing the totality of the nasal cavity. The scan realized with contrast injection has evidence an extended tumor of the nasal cavity, orbit (Figure 2) the patient has benefited from a preoperative embolisation, and the operative act was marked by pleading at the slightest touch; after a multidisciplinary staff: decision of radiotherapy

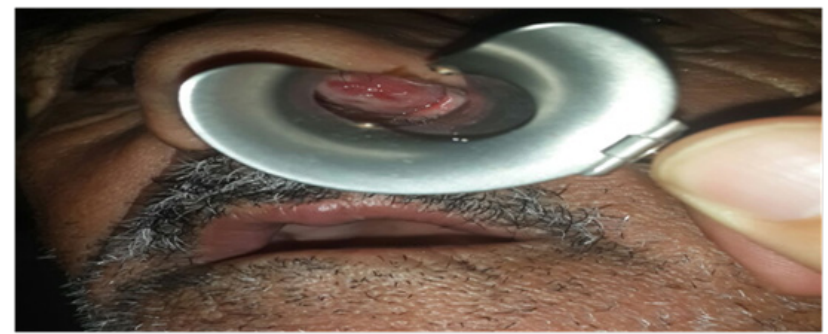

Figure I Mass of the left nasal cavity reddish in contact with the septum.

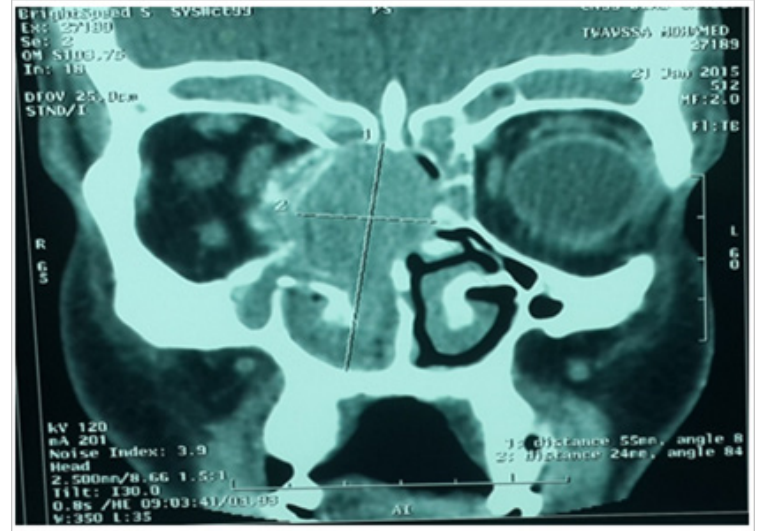

Figure 2 Frontal sections: filling of the right nostril with lysis intersino-nasal wall and the iinner wall of the orbit. 


\section{Discussion}

Hemangiopericytoma nasal sinus is a vascular tumor; developed from Mesenchymal stem cell differentiation has pericytaire ${ }^{2}$ few symptoms initially, it is diagnostic difficult. The clinicians should be alert by persistent unilateral nasal symptomatology and the endoscopic appearance of a tumor polypoid raspberry gray. ${ }^{3}$ The diagnosis is histological, but biopsies are delicate, given the risk hémorragique. The malignant potential of this tumor involves surgical excision ${ }^{3,4}$ the pretherapeutic includes a nasal sinus scan with iodine injection and a magnetic resonance imaging (IRM). ${ }^{5}$ Some after a arteriography with embolisation preoperative. La surgical technique remains the reference paralateronasal way but resections endoscopically have been recent found. ${ }^{6}$

\section{Conclusion}

The hemangiopericytoma sinonasal differs from other locations of hemangiopericytoma by its malignity rank lowest and best rate survive. The diagnostic difficulty is still major problem especially as clinical elements are not specific and architectural study should depart several diagnoses. A post operative monitoring during short is recommended.

\section{Acknowledgements}

None

\section{Conflict of interest}

The author declares no conflict of interest.

\section{References}

1. Vikneswaran T, Gendeh BS, Tan VE, et al. Sino-nasal hemangiopericytoma-a rare tumor. Med J Malaysia. 2005;60(4):485-488.

2. Stout AP, Murray MR. Hemangiopericytoma: a vascular tumor featuring Zimmermann's pericytes. Ann Surg. 1942;116(1):26-33.

3. Thompson LDR, Fanburg Smith JC, Wenig BM. Borderline and low malignant potential tumours of soft tissues. ALPF Medical Research. 2005.

4. Dandekar M, McHugh JB. Sinonasal glomangiopericytoma: case report with emphasis on the differential diagnosis. Arch Pathol Lab Med. 2010;134(10):1444-1449.

5. Mosesson RE, Som PM. The radiographic evaluation of sinonasal tumors: an overview. Otolaryngol Clin North Am. 1995;28(6):1097-1115.

6. Lin IH, Kuo FY, Su CY, et al. Sinonasal-type hemangiopericytoma of the sphenoid sinus. Otolaryngology Head and Neck Surgery. 2006;135:977979. 